\title{
ТРАНСФЕР ИННОВАЦИЙ В МЕЖОТРАСЛЕВОЙ КООПЕРАЦИИ: ЭФФЕКТ СИНЕРГИИ
}

Статья посвящена актуальным вопросам развития трансфера инноваций в межотраслевой кооперации и возникающего в результате этого эффекта синергии. Выделены основные факторы и преимущества, обеспечивающие получение синергетического эффекта, рассмотрены организационно-экономические, социальные и инновационно-технологические предпосылки к формированию межотраслевого сотрудничества.

Исходя из объективных предпосылок рассмотрена возможность кооперации фармацевтической и пищевой промышленности. Дополнительно представлен мировой опыт в части межотраслевого сотрудничества данных отраслей. Источником экономического эффекта от кооперации фармацевтической и пищевой промышленности является возможное снижение затрат на разработку и внедрение инноваций, социального эффекта - улучшение доступности и качества фармацевтических препаратов и продуктов питания, увеличение ассортимента продукции.

В качестве отечественного примера кооперации фармацевтической и пищевой промышленности в статье представлена разработка технологии комплексной переработки семян льна с получением фитопрепарата, обладающего антиаллергенной активностью на основе льняного масла и лигнанов. В результате переработки семян льна получены лигнансодержащая фракция, которую использовали для производства биологически активной добавки к пище, и мука льняная. Возникший побочный продукт в виде муки позволил снизить срок окупаемости инновационного проекта и дал возможность получить дополнительный экономический эффект.

Ключевые слова: управление, инновации, синергия, фармацевтическое предприятие, пищевая промышленность, кооперация, кластер.

Для цитирования: Дудан М. А. Трансфер инноваций в межотраслевой кооперации: эффект синергии // Труды БГТУ. Сер. 5, Экономика и управление. 2021. № 1 (244). С. 163-168.

\section{A. Dudan}

Belarusian State Technological University

\section{TRANSFER OF INNOVATIONS IN INTERSECTORAL COOPERATION: SYNERGY EFFECT}

The article is devoted to the topical issues of the development of the transfer of innovations in intersectoral cooperation, and the resulting synergy effect. The main factors and advantages that provide a synergistic effect are highlighted. Organizational-economic, social and innovative-technological prerequisites for the formation of intersectoral cooperation are considered.

Based on objective assumptions, the possibility of cooperation between the pharmaceutical and food industries was considered. Additionally, the world experience in terms of intersectoral cooperation of these industries is presented. The source of the economic effect from the cooperation of the pharmaceutical and food industries is a possible reduction in costs for the development and implementation of innovations, a social effect - an improvement in the availability and quality of pharmaceuticals and food products, an increase in the product range.

As a domestic example of cooperation between the pharmaceutical and food industries, the article presents the development of a technology for integrated processing of flax seeds with the production of a phytopreparation with antiallergenic activity based on flaxseed oil and lignans. Flaxseed flour and lignan-containing fraction were obtained as a result of processing flax seeds. The lignan-containing fraction was used for the production of a biologically active food supplement. Reduction of the payback period of the innovative project and additional economic effect was obtained from the by-product flaxseed flour. cluster.

Key words: management, innovation, synergy, pharmaceutical company, food industry, cooperation,

For citation: Dudan M. A. Transfer of innovations in intersectoral cooperation: synergy effect. Proceedings of BSTU, issue 5, Economics and Management, 2021, no. 1 (244), pp. 163-168 (In Russian). 
Введение. Межотраслевая кооперация играет важную роль в повышении эффективности экономической деятельности. Особенно велико ее значение для продвижения инноваций, внедрение которых связано с высоким коммерческим риском, поскольку многие инновационные проекты не окупают инвестированных в них средств. Увеличение доходов от реализации инновационных проектов возможно за счет синергетического эффекта в результате более широкого использования новых технологий в рамках межотраслевой кооперации.

Основная часть. Синергетический эффект в межсотраслевой кооперации. В последнее время особенно часто проявляются тенденции к кластеризации в инновационных процессах, позволяющие объединить ресурсы и навыки различных участников, а также сократить издержки по проведению исследований и разработок. При этом взаимовыгодные партнерские отношения оказывают влияние не только на стоимость и качество проводимых исследований и получаемых в результате продуктов, но и уменьшают степень риска и неопределенности, создавая основу для формирования конкурентных преимуществ [1].

Кластер как элемент инновационной инфраструктуры способствует активизации инновационной деятельности путем формирования вертикальных и горизонтальных связей за счет накопления знаний коммерческого и производственного характера и их быстрого распространения, поддержания внутренней конкуренции и сотрудничества, как способа генерирования новых идей и возможностей, позволяющего привлечь инвестиции на международном уровне и государственно-частного партнерства [2].

Отличительной особенностью кластерной экономики является возникновение положительного эффекта синергии. Межотраслевой синергетический эффект выражается в повышении результативности деятельности на основе использования различных видов инструментов, в том числе инновационных, в деятельности взаимосвязанных организаций за счет создания новой продукции, а также возникновения ее новых качеств и конкурентных преимуществ.

Среди факторов, которые обусловливают синергетический эффект, можно выделить следующие: объединение материально-технических, трудовых и финансовых ресурсов отраслей; применение традиционных знаний в новой области; увеличение мобильности персонала; осуществление трансфера технологий, ускоряющего инновационные процессы и др.

Синергетический эффект связан с получением ряда преимуществ, включая расширение спектра услуг и выпускаемой продукции; масштабирование результатов; сокращение затрат; снижение коммерческих рисков; повышение инвестиционной привлекательности новой структуры; возможность освоения новых рынков сбыта и др.

Драйвером отраслевой кооперации является рыночный механизм «выгодности» более тесного взаимодействия организаций вследствие снижения ряда издержек и возникновения положительных обратных связей, обеспечивающих интенсивное развитие всех организаций, связанных отношениями в рамках кластера.

На современном этапе развития кластеры чаще всего возникают и формируются в инновационных отраслях, именно там, где уже существуют или предполагаются научные прорывы, могут быть созданы современные продукты и технологии, формирующие новые рынки и организации [3]. Согласно М. Портеру, необходимо также учесть, что конкурентными преимуществами обладают союзы смежных и обслуживающих отраслей: сферы поступления и использования сырья, полуфабрикатов, оборудования. Поэтому при формировании кластера, как правило, рассматриваются родственные и поддерживающие отрасли. Ключевые предпосылки эффективной кооперации укрупненно можно разделить на следующие группы:

- организационно-экономические;

- социальные;

- инновационно-технологические [4].

Ключевые предпосылки кооперации фармацевтической и пищевой промышленности. Фармацевтическая промышленность в Республике Беларусь относится к группе высокотехнологичных отраслей. Конкурентоспособность фармацевтических предприятий обеспечивается в первую очередь за счет широкого использования достижений научно-технического прогресса. Лидирующее положение организаций данной отрасли увязывают с использованием достижений генетической и клеточной инженерии, биотехнологий, позволяющих разрабатывать и производить препараты со значительно улучшенными фармакокинетическими свойствами, хорошей переносимостью и высокой стабильностью.

Формирование кластера с участием фармацевтической промышленности требует определения производств, кооперация с которыми позволит получить максимальный синергетический эффект. Для этого целесообразно оценить взаимозависимость отдельных отраслей и секторов экономики путем анализа системы статистических таблиц «Затраты - Выпуск» [5]. На основании статистических данных по группе фармацевтических продуктов был проведен отбор основных отраслей конечного спроса (конечного потребления, валового накопления и экспорта) по обрабатывающей промышленности с долей более $1 \%$ (рис. 1). 


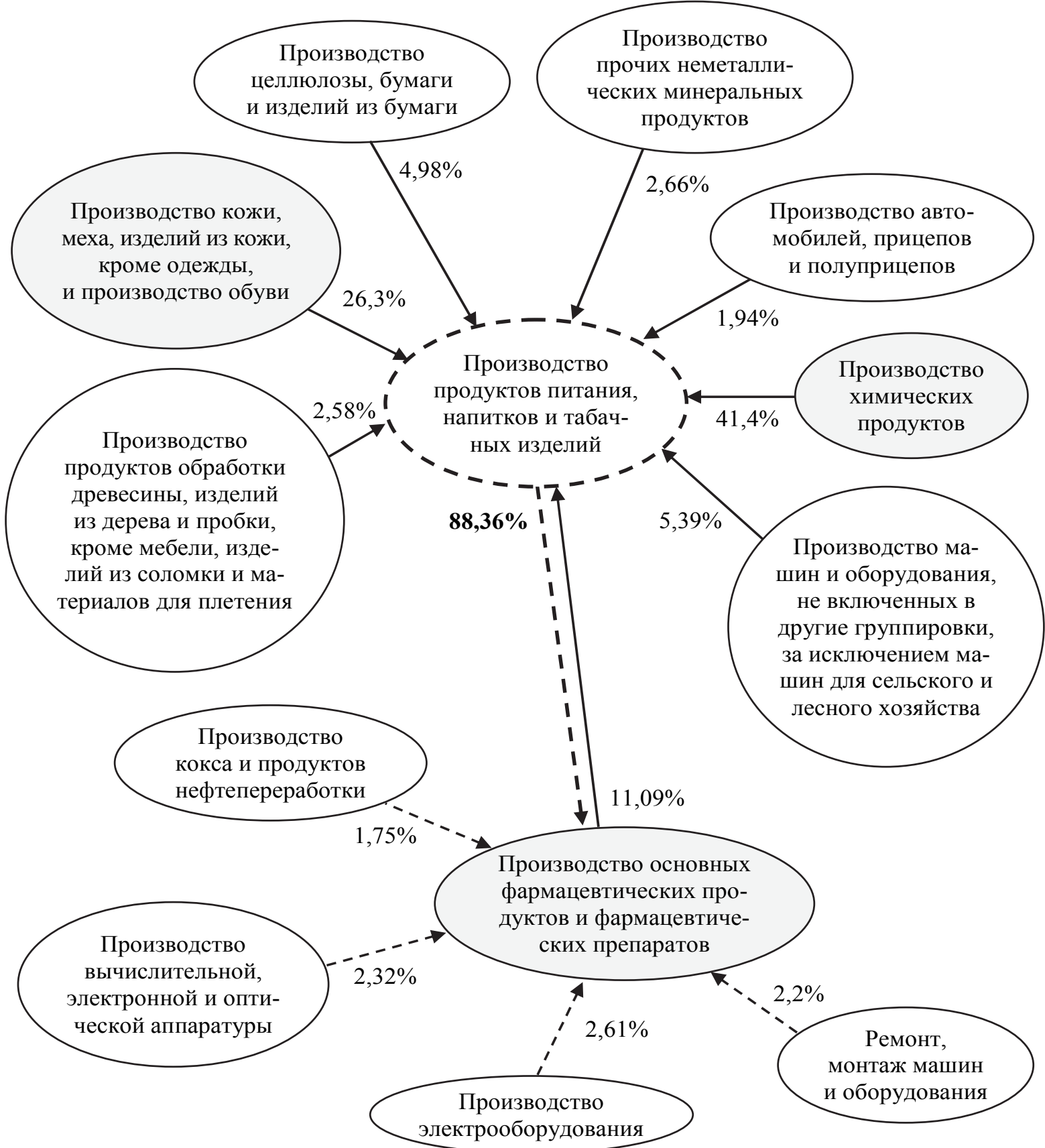

Рис. 1. Схема использования товаров и услуг в ценах покупателей

(Составлено автором на основании системы таблиц «Затраты - Выпуск» Республики Беларусь за 2018 г. [5])

Из отраслей обрабатывающей промышленности наибольший удельный вес потребления фармацевтической продукции приходится на производство продуктов питания, который составляет $88,36 \%$. При этом наблюдается его увеличение к предыдущему году на 6,47 п. п.

Структурный анализ производства основных фармацевтических продуктов по потребляемым группам товаров обрабатывающей промышленности позволяет выделить следующие основные группы: вещества химические и продукция химическая $(48,14 \%)$, бумага и изделия из бумаги $(9,96 \%)$, изделия резиновые и пластмассовые
$(9,06 \%)$, изделия минеральные неметаллические прочие $(8,02 \%)$, продукты пищевые, включая напитки, и табачные изделия $(6,25 \%)$.

Таким образом, фармацевтика, с одной стороны, в значительной степени использует продукцию пищевой промышленности, а с другой в большом количестве потребляется при производстве продуктов питания.

Дополнительный анализ по группе пищевых продуктов показал, что они потребляются больше всего в следующих отраслях обрабатывающей промышленности: производство химических продуктов $(41,4 \%)$, производство кожи, меха, изделий 
из кожи, кроме одежды и обуви $(26,3 \%)$, производство основных фармацевтических продуктов и фармацевтических препаратов (11,09\%). В свою очередь структуру основных групп товаров при производстве продуктов питания составляют следующие товары: изделия резиновые и пластмассовые $(23,46 \%)$, бумага и изделия из бумаги $(19,51 \%)$, вещества химические и продукция химическая $(17,99 \%)$, изделия минеральные неметаллические прочие $(8,2 \%)$, кокс и нефтепродукты $(7,22 \%)$.

Таким образом, можно отметить, что наиболее тесные хозяйственные связи фармацевтическая промышленность имеет с производством продуктов питания, что является аргументом в пользу такой кооперации.

Важным аргументом в пользу межотраслевого сотрудничества фармацевтики и пищевой промышленности может стать возможный дополнительный синергетический эффект в сфере здравоохранения. Всемирная организация здравоохранения (BО3) поднимает вопросы важности и целесообразности межсектрального сотрудничества. ВО3 определяет три основных сектора, с которыми это сотрудничество возможно и полезно: сельское хозяйство и питание, образование и культура, а также окружающая среда. Многочисленные практические примеры и исследования подтверждают не только возможности улучшения здоровья населения, но и реальные экономические и социальные выгоды, достигаемые в результате межотраслевой кооперации этих отраслей [6].

Растущий интерес к проблеме улучшения здоровья в Европе и США привел к появлению совершенно новых «функциональных» продуктов в итоге сотрудничества между пищевой промышленностью и фармацевтической индустрией. В настоящее время ведется множество исследований на предмет изучения функциональных свойств продуктов питания. Мировой и отечественный опыт показывает, что дополнительное обогащение продуктов питания массового потребления комплексом биологически активных добавок с широким спектром терапевтического действия до уровня, соответствующего физиологическим потребностям человека, - это наиболее эффективный и экономически доступный путь ликвидации дефицитных состояний (витаминной, минеральной недостаточности, анемии, дефицита йода) и повышения резистентности организма к неблагоприятным факторам среды. Добавление к обычной пище этих функциональных компонентов позволяет создать совершенно новый класс продуктов, которые благодаря своим оздоровительным свойствам пользуются все большим спросом. Разрабатываемые технологии производства продуктов питания на основе пищевых растительных композитов должны стать рецептом улучшения здоровья потребителя и способом снижения экономических потерь национальных бюджетов на здравоохранение.

Объединение фармацевтики и пищевой промышленности соответствует международному опыту. Food and Drug Administration в США управление, которое занимается контролем качества пищевых продуктов, лекарственных препаратов. С точки зрения бизнес-процессов пищевое производство ближе к производителям БАДов, чем лекарств. Так как у таких предприятий единый рынок труда, то они могли бы скооперироваться для подготовки специалистов. Для пищевого производства сотрудничество с фармацевтическим кластером было бы интересно, но для этого необходимо создать соответствующую инфраструктуру.

Таким образом, кооперация фармацевтической и пищевой промышленности в инновационной сфере способна стать источником синергетического эффекта как в экономической, так и в социальной сфере.

Источником экономического эффекта является снижение затрат на разработку и внедрение инноваций за счет их масштабирования и более широкого применения. Кроме того, объединение усилий разнопрофильных специалистов и организаций к разработке нововведений позволяет увеличить ресурсы, необходимые для развития инновационной деятельности.

В процессе научно-исследовательской деятельности фармацевтического предприятия может получиться результат, отличный от заданной цели. Нередко возникают случаи, когда в процессе исследований получают продукты для смежных отраслей. Фармацевтические исследования могут «делиться» не только своим основным продуктом (действующим веществом и лекарственным средством), но и побочным продуктом, применяемыми технологиями. Сопутствующим экономическим эффектом в данном случае может стать снижение себестоимости продукции, появление новых рынков сбыта и пр.

Социальный эффект проявляется в улучшении доступности и качества фармацевтических препаратов и продуктов питания, увеличении ассортимента продукции и способствует тем самым общему повышению качества жизни и системы здравоохранения в частности.

Отечественный опыт кооперации. В качестве успешного примера кооперации фармацевтической и пищевой отраслей Беларуси можно привести создание технологии комплексной переработки семян льна с получением фитопрепарата, обладающего антиаллергенной активностью на основе льняного масла и лигнанов, выполняемую в рамках ГП «Импортозамещающая фармпродукция» [7]. 


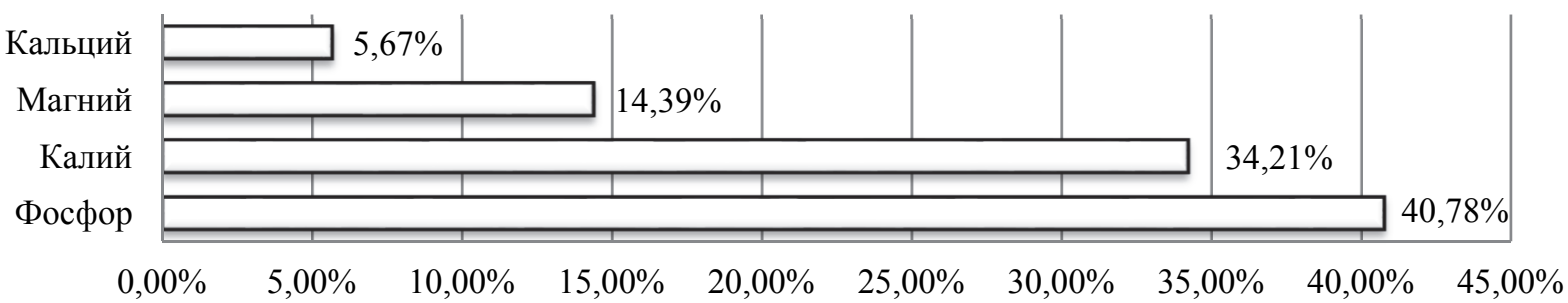

Рис. 2. Анализ минерального состава зольных остатков семян льна

(Составлено автором на основании [7])

В Республике Беларусь к традиционной национальной растительной культуре относится лен, а льняное семя является одним из самых богатых источников $\alpha$-линоленовой кислоты, пищевых волокон и лигнанов. Лигнаны обладают широким спектром биологической активности: являются мощными антиоксидантами, фитоэстрогенами, обладают противовоспалительными и противоопухолевыми свойствами, повышают общий иммунитет. Семена льна масличного являются источником белка, ценность и функциональные свойства которого обусловлены высоким содержанием незаменимых аминокислот (рис. 2). В исследуемых сортах льна содержание белка колеблется от 19,07 до $23,92 \%$.

В последние годы в Республике Беларусь в рамках ряда научно-технических программ выполнены исследования по селекции и интродукции сортов льна масличного, а также по увеличению стабильности льняного масла. Традиционно отечественная переработка льняного семени заключалась в получении льняного масла, в то время как на фармацевтическом рынке таких стран, как Канада и США, представлены препараты, основным компонентом которых является лигнан SDG, выделенный из льняного семени. Поэтому исследования направлены на создание отечественной технологии комплексной переработки семян льна масличного с возможностью получения не только льняного масла, но и других полезных продуктов [7].

В результате исследования, целью которого являлась разработка научно-обоснованной технологии переработки семян льна масличного с получением лигнансодержащей фракции, был получен побочный продукт для пищевой промышленности в виде муки.
Полученная лигнансодержащая фракция из оболочек семян льна масличного сорта отечественной селекции Солнечный создавалась для использования в качестве компонента биологически активной добавки к пище для профилактики ряда заболеваний: рака молочной железы и простаты, кардиоваскулярной болезни, туберкулеза кожи, диабета, а также влияние лигнанов на репродуктивные функции человека.

Экспериментально установленные технологические параметры переработки семян льна стали основой технологии получения лигнансодержащей фракции, которую использовали для производства на УП «Минскинтеркапс» биологически активной добавки к пище «Лигнокапс», и муки льняной. Возникший в результате межотраслевого сотрудничества побочный продукт позволил снизить срок окупаемости инновационного проекта и, соответственно, дал возможность получить дополнительный экономический эффект.

Выводы. Развитие межотраслевой кооперации на основе кластеров является важным фактором повышения эффективности инновационной деятельности. Потенциал кластерных образований во многом определяется технологической и организационной взаимозависимостью отраслей. Как показал межотраслевой анализ, наиболее высокий уровень такой зависимости наблюдается между видами деятельности по производству продуктов питания и фармацевтических изделий. Формирование кластера на базе данных отраслей позволит существенно повысить их инновационный потенциал и эффективность деятельности за счет разработки и внедрения нововведений.

\section{Список литературы}

1. Бондаренко Н. Е. Межфирменная кооперация как фактор инновационного развития // Вестник РЭУ им. Г. В. Плеханова. 2016. № 6 (90). С. 31-40.

2. Арсенов В. В. Основные предпосылки формирования кластеров // Наука и инновации. 2016. № 11. C. $37-41$.

3. Новикова И. В. Инновационный кластер - основа структурной перестройки национальной экономики // Банковский вестник. 2015. № 7 (624). С. 18-24.

4. Дудан М. А. Возможности кооперации фармацевтической и пищевой промышленности в Республике Беларусь // Вестник Полоцкого государственного университета. Сер. Д. Экономические и юридические науки. 2020. № 5. С. 15-23. 
5. Статистическая база данных Национального статистического комитета Республики Беларусь URL: www.belstat.gov.by (дата обращения: 31.01.2021).

6. World Health Organization. Intersectoral action for health: the role of intersectoral cooperation in national strategies for Health for All. / Department of Health Economic, Athens School of Public Health. 1986. $150 \mathrm{p}$.

7. Феськова Е. В. Технология получения лигнансодержащей фракции и муки из семян льна масличного: автореф. дис. ... канд. техн. наук: 05.18.07. Минск. 2015. 24 с.

\section{References}

1. Bondarenko N. Ye. Interfirm cooperation as a factor of innovative development. Vestnik REU im. G. V. Plekhanova [Bulletin of the PRUE G. V. Plnkhanova], 2016, no. 6 (90), pp. 31-40 (In Russian).

2. Arsenov V. V. The main prerequisites for the formation of clusters. Nauka i innovatsii [Science and innovation], 2016, no. 11, pp. 37-41 (In Russian).

3. Novikova I. V. Innovation Cluster - the basis of the restructuring of the national economy. Bankovskiy vestnik [Banking bulletin], 2015, no. 7 (624), pp. 18-24 (In Russian).

4. Dudan M. A. Cooperation opportunities of pharmaceutical and food industry of the Republic of Belarus. Vestnik Polotskogo gosudarstvennogo universiteta. Seriya D, Ekonomicheskiye i yuridicheskiye nauki [Herald of Polotsk State University], series D. Economic and jurisprudence, 2020, no. 5, pp. 15-23 (In Russian).

5. Statisticheskaya baza dannykh Natsional'nogo statisticheskogo komiteta Respubliki Belarus' [Statistical database of the National Statistical Committee of the Republic of Belarus]. Available at: www.belstat.gov.by (accessed 31.01.2021).

6. World Health Organization. Intersectoral action for health: the role of intersectoral cooperation in national strategies for Health for All. Department of Health Economic, Athens School of Public Health, 1986. $150 \mathrm{p}$.

7. Feskova A. V. Tekhnologiya polucheniya lignansoderzhashchey fraktsii i muki iz semyan l'na maslichnogo. Avtoref. dis. kand. tekhn. nauk [Technology of lignans-containing fraction and flour production from flaxseeds. Abstract of thesis cand. of techn. sci.]. Minsk, 2015. 24 p.

\section{Информация об авторе}

Дудан Марина Александровна - ассистент кафедры экономики и управления на предприятиях. Белорусский государственный технологический университет (220006, г. Минск, ул. Свердлова, 13a, Республика Беларусь). E-mail: dma18@yandex.ru

\section{Information about the author}

Dudan Marina Aleksandrovna - assistant lecture, the Department of Enterprise Economy and Management. Belarusian State Technological University (13a, Sverdlova str., 220006, Minsk, Republic of Belarus). E-mail:dma18@yandex.ru 